\title{
The Interaction of Image and Text In Modern Comics
}

\author{
Tom Lambeens and Kris Pint
}

\section{Introduction}

The combination of image and text is undoubtedly one of the most typical features of the comic strip genre. This combination in itself is, of course, far from new. Sequential images were already combined with textual elements in Egyptian hieroglyphs or medieval manuscripts and paintings. ${ }^{1}$ The comic strip as such evolved in the first half of the nineteenth century, with artists like Rodolphe Töpffer (influenced by William Hogarth), Wilhelm Busch and Pehr Nordquist, all of whom created stories that were easy to reproduce and combined words and images, albeit still strictly separated from each other. Inspired by the American newspaper comics of the early twentieth century, like Frederik Burr Opper's Happy Hooligan (1900) and Alphonse and Gaston (1901), the European comic strip started to integrate speech balloons into the image itself, with Hergé's Les Aventures de Tintin as its most prominent and best-known exponent. ${ }^{2}$ Initially conceived for the youth supplement of a Belgian newspaper, Tintin proved so successful that his adventures were soon published in book form as well. The emergence of real comic books meant an important evolution of comics, a move away from the rather transitory medium of the newspaper. Yet for a long time, comic books were mostly seen as children's entertainment. In the seventies, this view began to change with the emergence of the so-called "graphic novel," which featured more mature content and, at times, a more experimental style of drawing as well. A successful, recent example of this emancipation of the comic book genre is Logicomix (2008), by Apostolos Doxiadis, Christos Papadimitriou, and Alecos Papadatos. The book is conceived as a complex account of both the theories and the lives of the founders of modern mathematics and logics, like Bertrand Russell and Ludwig Wittgenstein - a far cry from the light-footed newspaper gags which gave "comics" their name.

1 See Lefèvre (2006) and Dierick and Lefèvre (1998) $13^{-22 .}$

2 For a comprehensive discussion of the "history" of the speech balloon, see Lefèvre (2006).

(C) TOM LAMBEENS AND KRIS PINT, 2015 | DOI 10.1163/9789004270848_014

This is an open access chapter distributed under the terms of the Creative Commons AttributionNoncommercial 3.o Unported (CC-BY-NC 3.0) License. 
The large number of recent films based on comic books, like David Cronenberg's A History of Violence (2005), Frank Miller's and Robert Rodriguez' Sin City (2005), Zack Snyder's 300 (2006, also based on a graphic novel series by Frank Miller) and more recently, Steven Spielberg's The Adventures of Tintin (2011), seems to reveal the close affinity between both media. They can both be categorised as visual narratives and often use similar techniques (montage, point of view, split screen). But as Hans-Christian Christiansen argues in his "Comics and Film: A Narrative Perspective" (2000), this mutual influence should not cause us to forget the important aesthetic differences between both media. ${ }^{3}$ One of the distinctive features of mainstream comics seems to be precisely that co-presence of written text and image, or as Robert C. Harvey puts it in his "Comedy at the Juncture of Word and Image" (2007): "the essential characteristic of 'comics' - the thing that distinguishes it from other kinds of pictorial narratives - is the incorporation of the verbal content."4

Precisely because of this characteristic combination of text and image, the readers of comics are caught between the act of perceiving and the act of reading. Not only the medium itself, but also the relatively new theoretical research on the genre continues to struggle with this duality between text and image. ${ }^{5}$ This often inhibits an exploration of the full potential of the interaction between text and image so crucial to the genre. In this paper, we introduce another duality, one between code and sensation. We argue that exploring the interaction between both axes (the axis of word/image and that of code/sensation) provides interesting perspectives for both the analysis and creation of comics. We will illustrate this by examining the works of two of the founding fathers of European comics, Hergé and Franquin, and those of some contemporary, Western avant-garde artists like Jochen Gerner, Dominique Goblet, Bert Van der Meij, and Chris Ware, and by discussing Front Back, an experimental comic book by Tom Lambeens, co-author of this paper.

\section{Word versus Image}

We will start with a discussion of the first axis, word-image. In his standard work The System of Comics (1999, translated in 2007), Thierry Groensteen distinguishes between the image zone, which creates an illusion of three-dimen-

3 Christiansen (2000) 107-23.

4 Harvey (2007) 75 .

5 See especially Groensteen (1997, 2007 and 2008), Lefèvre and Baetens (1993), McCloud (1993) and Peeters (1991). 
sionality, and the text zone, which remains faithful to the "bi-dimensional materiality of the writing surface." 6

Such an approach, which clearly separates word from image, can be very fruitful for the analysis of the works of someone like Hergé. In Les Aventures de Tintin we see how neatly he splits the narration into different panels and how, within each panel, he separates the visual and the verbal elements. The visual elements are predominantly located in the lower half of the panel. The background of the image is often filled with details, while the figures in the foreground lack detailing. The words are restricted to the captions and the speech balloons, which are almost invariably placed at the upper half of the panel. The same neutral typography is used to render the words of friends and foes, young and old, male and female. This indicates that the text is only there to be read, like one would read words in a novel. Nonetheless, it is interesting to note that the text, with its typographic "stir" of curves and straight lines, visually corresponds with the busy detailing in the background of the images, while the ample spacing of the words in the captions and speech balloons corresponds with the "airy" figuration of the characters (Figure 12.1). Yet despite this careful, nuanced harmony between text and image, both zones remain strictly separated from each other.

In the works of another important master of the genre, Franquin, the opposition between the zones becomes far less self-evident. In Franquin's typical "busy" style of drawing we see more verbal elements appearing in the image zone. If we look at comic strips like his Gaston Lagaffe series about a lazy yet inventive office clerk, we can see that word clouds are placed in a more dynamic, fanciful way than in Hergés works and that grotesque onomatopoetic forms (indicating e.g. shouting, explosions and other noises) play an active part in the overall figurative composition of the panel. ${ }^{7}$

In some contemporary avant-garde comic books, created by artists like e.g. Dominique Goblet and Bert Van der Meij, the merging of the two zones is pushed to its limits, by integrating into the visual composition not only onomatopoetic forms, but "normal" words as well. Figure 12.2 illustrates this radical blending in Goblet's Faire Semblant C'est Mentir (2007) [Faking is Lying too]. We see how Goblet rejects the uniform rendering of words in a single font. The text also escapes the tyranny of the speech balloon and sometimes even pushes the visual representation to the background of the panel. In contrast with the neutral fonts used by artists like Hergé, the typography Goblet and Van der Meij use is frequently adapted to the specific context of the image.

6 Groensteen (2007) 69-70.

7 Franquin (2009) 39 . 

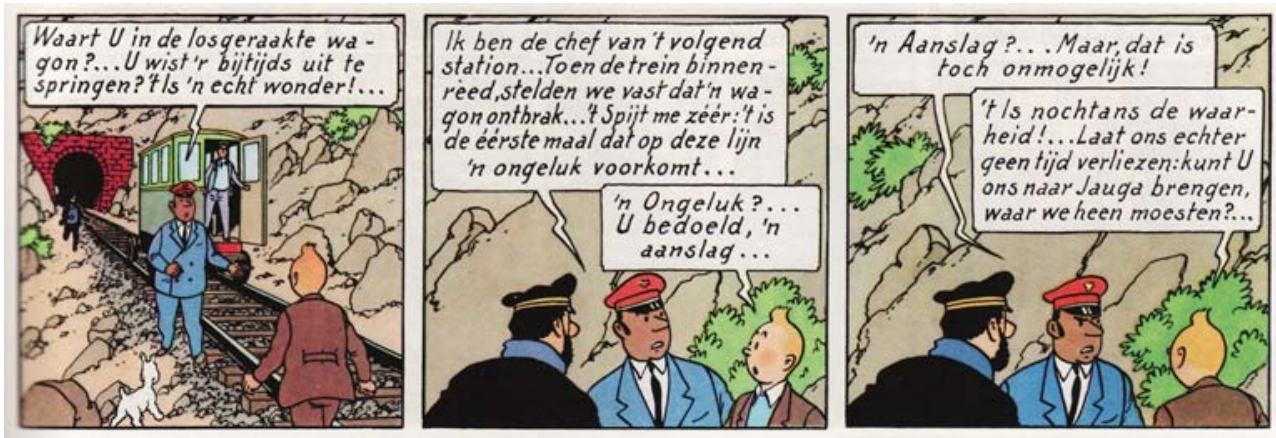

Figure 12.1 Hergé, De Zonnetempel (Doornik: Casterman, 1977), p. 17.

(C) HERGÉ/MOULINSART, 2012

It is here that the analytical framework of Groensteen reveals its limits. It cannot completely grasp the specific interaction between the verbal and visual elements in Franquin, Goblet and Van der Meij, precisely because of its overly exclusive focus on the opposition between word and image. When we want to understand how textual elements start to function visually and an image starts to function as a text, we should take two other notions into consideration: sensation and code.

\section{Sensation Versus Code}

The notion "code" has the advantage of transcending the classic duality between word and image. Words are just one (linguistic) form of code. When we read comic strips, we must also decode the images: we use narrative and cultural codes to make sense of the depicted actions and scenes, but also visual codes to recognize the different characters and locations. Just like other codes, a visual code works by conventions and (internal) analogies, an operation that bans the difference and repeats and stresses the general, the similar. The coded image can refer to another set of images. A drawing of Garfield primarily refers to other, similar drawings of this cartoon figure, allowing us to recognize it as the same character in different cartoons, but can also refer to a referent in reality: the drawn cat has some general features in common with a real cat. In his Understanding Comics. The Invisible Art (1993), Scott McCloud points out that this "codification" of the image is gradual, going from a photorealistic, detailed rendering to an archetype and, in extremis, to an abstract sign. ${ }^{8}$ Yet even that

8 McCloud (1993) 52-53. 

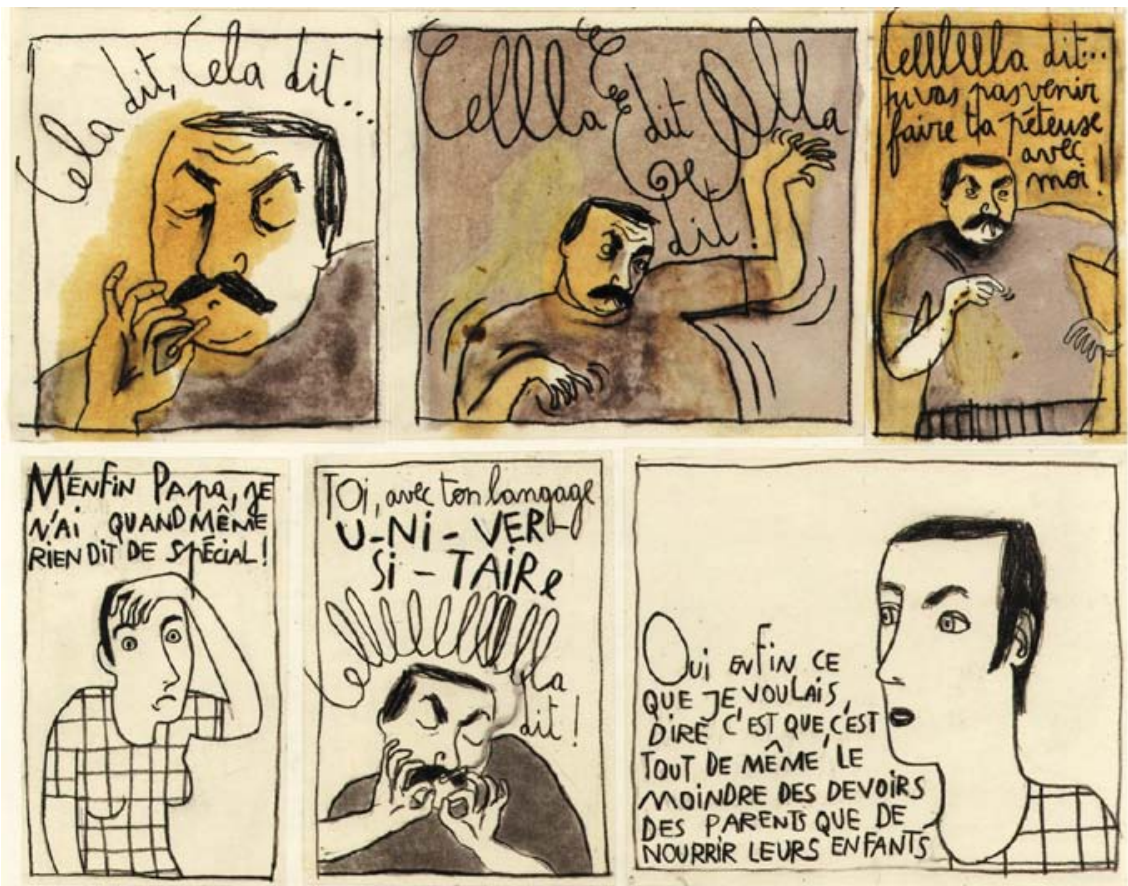

FIgure 12.2 Goblet, D., Faire Semblant C'est Mentir (Paris: L'Association, 2007), p. 21.

(C) DOMINQUE GOBLET \& L'ASSOCIATION, 2007

sort of view on the relation between text and image as a gradual transition, rather than a strict opposition (as with Groensteen), still ignores what it is in this codification that resists the code or even disrupts it: visual sensation. It is striking that the medium of comics, which belongs to the plastic arts, is so seldom analysed from a visual perspective. Pascal Lefèvre already pointed out this important omission in the theoretical reflection on the medium in his "Recovering Sensuality in Comic Theory" (1999). ${ }^{9}$ By adding the term "sensation" to the toolbox of comic strip theory, we want to provide an instrument to examine this neglected visual, plastic component of the genre.

Unlike "decoding," which refers to a mental activity, an act of reading that abstracts from the actual perception of the code or the materiality of the medium, "sensing" is far more physical: a sensation affects the body, making one aware of the physical act of experiencing something. Every sensation is unique, as it is related to a specific body at this specific time-space, and thus differs from any other sensation. This difference obscures the construction of a code 
that represses the dissimilar. In his Francis Bacon: The Logic of Sensation (1981, translated in 2003), Deleuze's interpretation of sensation goes further than the "sensual reading" Lefèvre advocates. Rather than merely an aesthetic, bodily experience, sensation arises in a confrontation with forces that undo our normal outlook and present the perceiving body with unknown affects that cannot be reduced to familiar (hence "coded") emotional or aesthetic schemata. Deleuze uses the notion of sensation to analyse modern art as a way of exploring "percepts" and "affects" that no longer mimetically refer to an external reality or an internal psychological state. Even if modern art possesses referentiality - e.g. interpreted along the lines of a mimetic code, the black strokes in Wheatfield with Crows (1890), one of Vincent Van Gogh's final paintings, refer to the birds we all know, just as, within the framework of a psychological/biographical code of interpretation, these evocative strokes can be "decoded" as the expression of Van Gogh's mental discomfort- it simultaneously presents the difference too. ${ }^{10}$ In modern painting, artists reveal this difference by not hiding brush-strokes or clots of paint, but actually accentuating their materiality. At the representational level, they try to deform what is depicted, to overload it with detail or to supplement it with a specific visual rhythm, so we can only perceive it as a sensation, and not read it as a code. We can see this e.g. in the work of Cézanne, who exaggerates colours and forms, or in the work of Bacon, who depicts the human body almost beyond recognition, and, in so doing, stirs a strong response in his spectators. ${ }^{11}$

The Deleuzian interpretation of the notion of "sensation" can be linked to the that of "defamiliarisation" or ostranenie, discussed by Victor Shklovsky in his "Art as Technique" (1917). Through repeated dealings with the same objects or situations, our sensual perception becomes infected by a hidden coding, causing us to ignore all the different experiences they evoke. For Shklovsky, art tries to disrupt this codification of the experience by searching for formulations that allow us to see familiar things and situations as if they were experienced for the very first time: "And art exists that one may recover the sensation of life; it exists to make one feel things, to make the stone stony. The purpose of art is to impart the sensation of things as they are perceived and not as they are known."12 Shklovksy's remark makes clear that it would be incorrect to simply equate the axis of code/sensation with the axis of realism/non-realism. The point Shklovksy makes is precisely that a non-realistic artistic representation of a stone can in fact be a more real evocation of a stone than an easily recog-

\footnotetext{
10 Deleuze (2003) 61-69, 8o.

11 Ibid., 25-31, 79.

12 Shklovsky (1965) 12.
} 
nizable photograph or drawing. Likewise, the splashes of paint on a non-figurative painting can be seen as more "real" than any "normal" representation, which implies illusion. And there is also no reason why a seemingly "realistic" painting could not evoke sensation by showing, in the representation of the familiar, the "coded" reality, the non-evident, the unknown, the unreality of actual sensual experience. We can easily recognize the mimetic code of the crows and the rural setting in van Gogh's Wheatfield, yet through their actual materiality and position on the canvas emerges a sensation that goes beyond the realistic representation of a typical rural landscape.

Obviously, such sensations that escape from the code are much easier to create in paintings, where the narrative and referential aspects can be reduced to a minimum. In a comic strip, these possibilities quickly come to a dead end, because the sequence of images inevitably installs narrative sequentiality, repetition and hence code. Most comic strips use characters, and we can only recognize a character if it reappears in a fairly recognizable - hence coded - way throughout the different panels. The genre of the comic strip, therefore, cannot do without code. Pure sensation without any code is, indeed, simply impossible.

In contemporary avant-garde comics, we can distinguish two different reactions to this interaction between code and sensation. Some artists try to avoid this duality altogether by extending the anti-sensual realm of the text to the images themselves and striving for an ever more purified code, with as little "sensual" surplus as possible. Due to the semiotic and narratological background of comic strip theory, which emerged from literature and film studies, it is not surprising that near exclusive attention has been given to such artists, like Hergé and more recently Chris Ware, whose "coded" works effectively illustrate the theoretical schemes.

If we are to give a quick overview of the development in what we could call the "school of repetition," we should, again, take Les Aventures de Tintin as a starting point. We have already discussed the absence of detail in Hergé's foreground figures, which makes them akin to the pictograms of Arntz and Neurath. With their Isotype (International System of Typographic Picture Education), they have tried to develop a universal language of pictograms in which the image completely coincides with a semantic concept, as we can see in Figure 12.3, Arntz's image of a boat. If we compare this image with Hergé's rendering of a boat in e.g. Le Temple du Soleil (1949) (Figure 12.4), we see the same kind of reductionism that preserves only the volume and the contour lines of the ship.

Inspired by Hergé's famous ligne claire-style and the pictograms of Arntz, Jochen Gerner's TNT en Amérique (2002) brings this "codification" of images to 


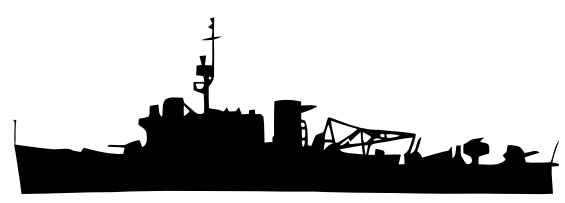

Figure 12.3 Arntz, G., Pictogram of a boat (1930). Accessible at http://www.gerdarntz. org/isotype
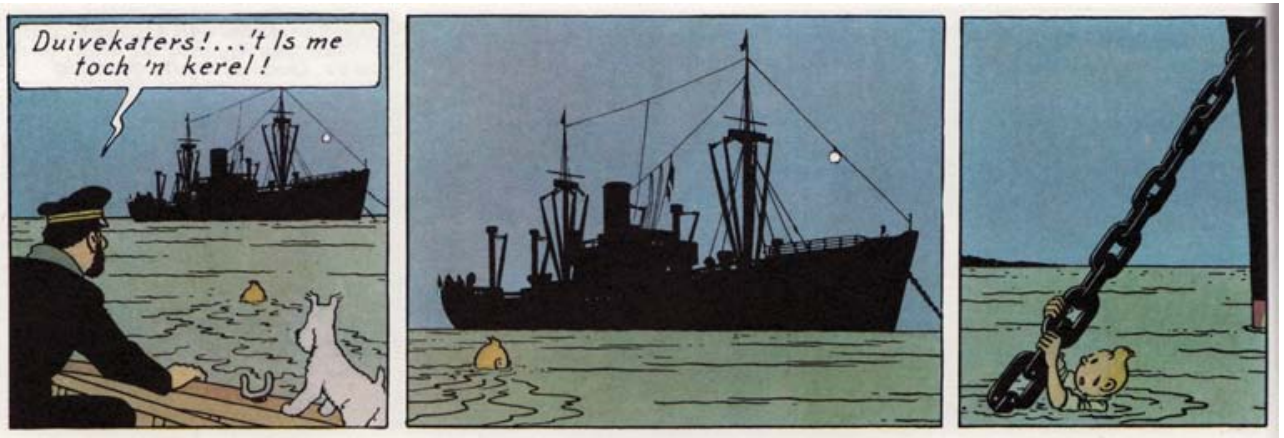

FIgURE 12.4 Hergé, De Zonnetempel (Doornik: Casterman, 1977), p. 6.

(C) HERGÉ/MOULINSART, 2012

a climax that flirts with abstraction. In this work - an adaptation of the famous Tintin en Amérique - Gerner covers entire panels with black paint, sparing only the most necessary words and images. The few images that escape the black pigment are reduced to pictograms which create playful variations on Arntz's famous set. This ironic operation breaks up both the code of the classical comic strip and the pictogram, but only to replace it with a third, idiosyncratic code - a strange pictorial universe that is Gerner's own creation (Figure 12.5).

In a more accessible, "mimetic" style than Gerner, Chris Ware, too, searches for the ultimate limits of codification by taking full advantage of the formal possibilities of the medium. A good example of this is Ware's Jimmy Corrigan: The Smartest Kid on Earth (2000). Ware tries to construct a clear overall structure for his story by using the same set of colours that are symbolically interrelated, and by copying identical curves and sometimes even whole panels throughout the strip, as we can see in Ware's Jimmy Corrigan, p. 117. Just like Hergé, he strives for visual purity, and digitally generated colouring offers him the ideal alternative to the unavoidable imperfections of manual colouring, which would reveal the materiality of the image. Ware aims to render a flower in a manner so conventional and "neutral" that the readers can project their 


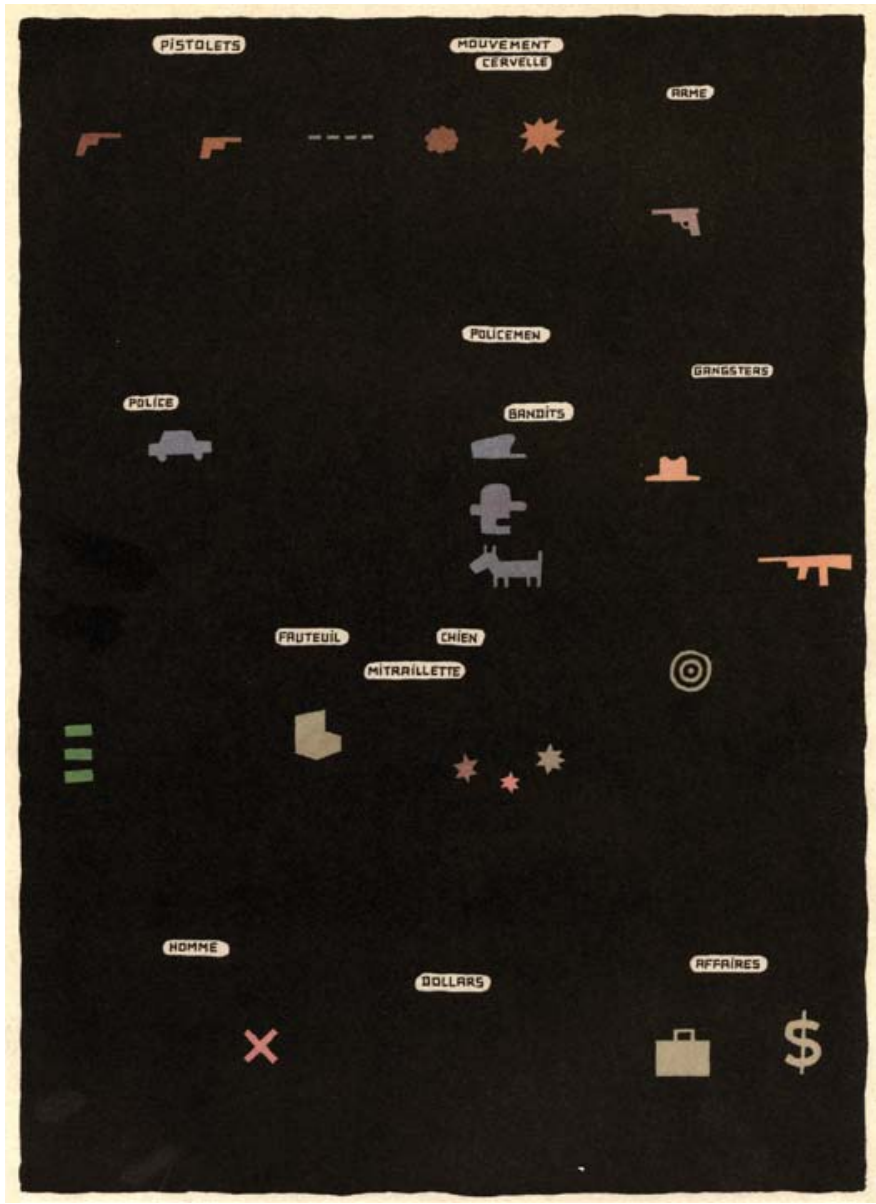

FIgURE 12.5 Gerner, J., TNT en Amérique (Paris: L'ampoule, 2002), p. 41. (C) L'AMPOULE, 2002

own subjective flower to fill in the image. ${ }^{13}$ Yet those coded images could never have a strong emotional effect, precisely because they lack surprise and thus sensation. The image is supplemented by the personal memory of the reader (to the pictogram-like flower he or she adds the knowledge of how real flowers look and smell), but this memory only activates what is already known, already experienced. The "sensual" power of the image emerges only when the expectation, i.e. the imagination of the reader, is surpassed and unsettled and a totally new experience is provoked. Therefore, we believe that the evocative, "sensational" power of Ware's Jimmy Corrigan is to be found on another level. Precisely by evacuating every visual sensation from the work itself, by using

See Peeters and Samson (2010) 133 -35. 
the same codified forms over and over again and by using pure, computer-generated areas of colour, the panels of Jimmy Corrigan evoke a sensation of despair, sadness and claustrophobia. This sensation cannot be visually located in the panels themselves, but instead resides in the reader's bodily resistance against this codification, against this closed, neurotic universe that does not provide a means of escape.

When we move away from the shadowless and dematerialised, "clean" worlds of Ware and Hergé and instead look for artists who no longer try to tame the sensual force of the image, we are brought back to Franquin as a key figure. His painstakingly detailed figures of the Gaston Lagaffe or Spirou-series are drawn with a whimsical line that varies in size. This "rhizomatic" style of drawing, so typical for Franquin, is the exact opposite of Hergé's absolute and neat ligne claire. Contrary to the static nature of a panel in a comic book, Franquin's dynamic line evokes a certain vitalistic agility and reveals the materiality of the drawing, namely ink on paper, something that is "repressed" in Hergé's perfect line. Obviously, Franquin also needs codification, and Gaston Lagaffe, just like Tintin, is a character that we can immediately recognize because of the coded repetition of certain features (his gigantic nose, green pullover and typical, stooped gait). Yet by cramming his panels full of details, Franquin also disrupts this code. For instance, he will never depict Gaston in profile: his trajectory never runs parallel with that of the image plane. This friction creates a sense of depth and accentuates the liveliness. When Gaston walks, rather unrealistically, you always see the tops and/or soles of his shabby slippers. ${ }^{14}$

These details function as visual "barbs" that turn the reader into a viewer who is arrested by the things he or she sees on the panel. Just like Hergé, Franquin's images are mimetic, but unlike Hergé's, they never belong to a universe of almost archetypical, unchanging figures and objects. They are simultaneously utterly unrealistic and perfectly recognizable. Franquin overloads them with details and never tries to mask the imperfections of his drawings, nor the imperfections in the story-world he evokes: his depicted objects are susceptible to decay and full of flaws. This makes his comic strips look less coded, because the code is always overtaken by the chaotic fluidity that marks the universe of Gaston \& co. We can easily illustrate this difference when we compare e.g. a boat from Hergé with a more "swinging" example by Franquin. Franquin's boat can initially be drawn "tighter" than Hergé's, but when, in an ensuing panel, it collides with a rock, it appears to be as liquid as the surrounding water itself (Figure 12.6). With Franquin things are never fixed into a single, clearly defined essence: depending on each situation, they acquire other attributes and reveal another transformation which never solidifies into a code. 

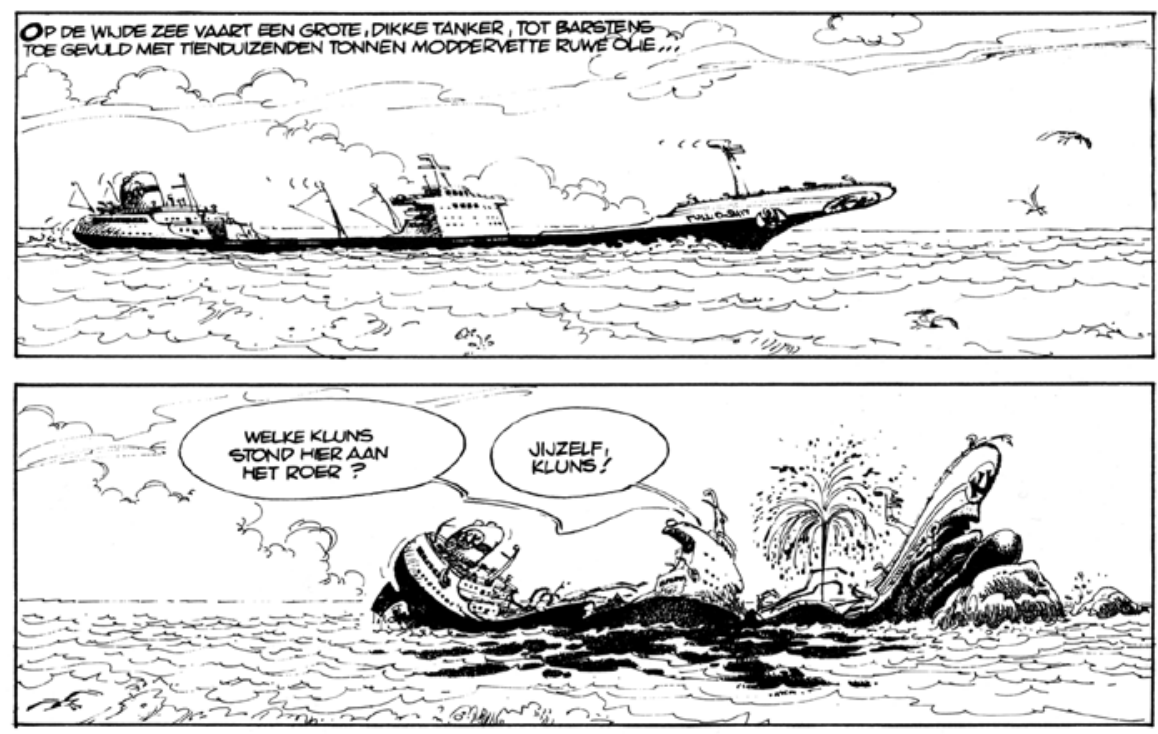

FIGURE 12.6 Franquin, Zwartkijken (Doornik: Glad ijs/Casterman, 20o8), p. 56.

(C) CASTERMAN S.A.

This constant flow of sensations can be achieved not only by constantly changing the form and the movement of the figures and objects, highlighting the difference between each appearance of these elements, but also by accumulating codes, overloading codes with other codes, hopping from one code to another in a never-ending motion. In line with Franquin, an artist like Blutch has developed other techniques to fight codification. He uses different codes, like Franquin uses different strokes and line sizes, to defy a clear-cut codification of his characters. Blutch does this by combining different styles of drawing in one strip and by switching between visual clichés and cultural conventions. He combines a typical pose from fashion photography with a film still and a contrapposto from the classical arts, or joins visual features to create an animal that can, at a time, be a cat, a horse and a dog, and thus can never be reduced to a single referent. ${ }^{15}$ In Le petit Christian (1999-2008), the main character constantly takes different shapes, ranging from realistically drawn movie heroes like John Wayne, Bruce Lee, and Marlon Brando to other comic strip characters like Lucky Luke and Tintin. ${ }^{16}$ By combining a multitude of codes in the same panel, he creates an sense of "overkill" that disrupts a clear reference to reality and that favours the sensation of the images themselves.

\footnotetext{
15 Blutch (2002) 11.

16 Blutch (1999) 27.
} 
Not just the images, but also the linguistic code of words can be made "sensual." Again we have to mention Franquin, who used to autograph his Gaston Lagaffe gags. This signature combines text with image in a unique conjunction: letters get lured away from their symbolical referentiality and become active characters in a kind of micro-gag. ${ }^{17}$ The same kind of "sensual" typography, in which the visual, active aspect becomes as important or sometimes even more important than the meaning of the words, can be found in the works of Van der Meij and Goblet. As we can see in the opening panel of De Winnaar, Van der Meij adapts the typography of his words to the onomatopoetic forms. ${ }^{18}$ The large, bold letters evoke the loud roaring of the motor, while the more subtle sound of loose screws is presented in a smaller font. What we get here is a kind of synaesthesia, where auditive impressions can be experienced visually. Of course, this synaesthetic sensation quickly turns into a code: the dominance of the words in the panels indicates "loudness," the size of the words indicates the increasing volume, and their repetition over different panels throughout the strip inevitably codes the visual impact of the typography.

Another good example can be found in Goblets Faire Semblant C'est Mentir. Figure 12.2 is a panel in which main character Dominique has an argument with her alcoholic father, who is irritated by her "academic language," specifically the way she uses the formal phrase "cela dit" [notwithstanding]. When Dominique pronounces the word, the typography is conventional and neutral. But when her father repeats this word five times, it is visually supplemented with curls and fringes, and becomes more erratic with every iteration. This in turn activates an act of decoding: the frills that we see are the visual manifestation of the accusation that his daughter is "putting on frills," and the size of the fonts reflects the increasing volume of his voice and the violent emotional impact on his daughter. But at the same time the panel creates a predominantly visual sensation, in which the typographic forms evoke a disturbing, oppressive atmosphere, a feeling of humiliation and frustration that is all in all "felt" more than it is "decoded."

In order to illustrate that the axis of code/sensation is not only a useful supplement for the analysis of comics, but also for their creation, we want to conclude with a short discussion of Front Back (2009), an experimental comic by Tom Lambeens that explores this very interaction between code and image. Even a brief glance at this comic book reveals that an analysis using the classic opposition of "word" and "image" is rendered impossible, as the "panels" only consist of squares of fully saturated primary and secondary colours. The

\footnotetext{
17 Franquin (2009) 39.
}

18 Van der Meij (2005) 1. 


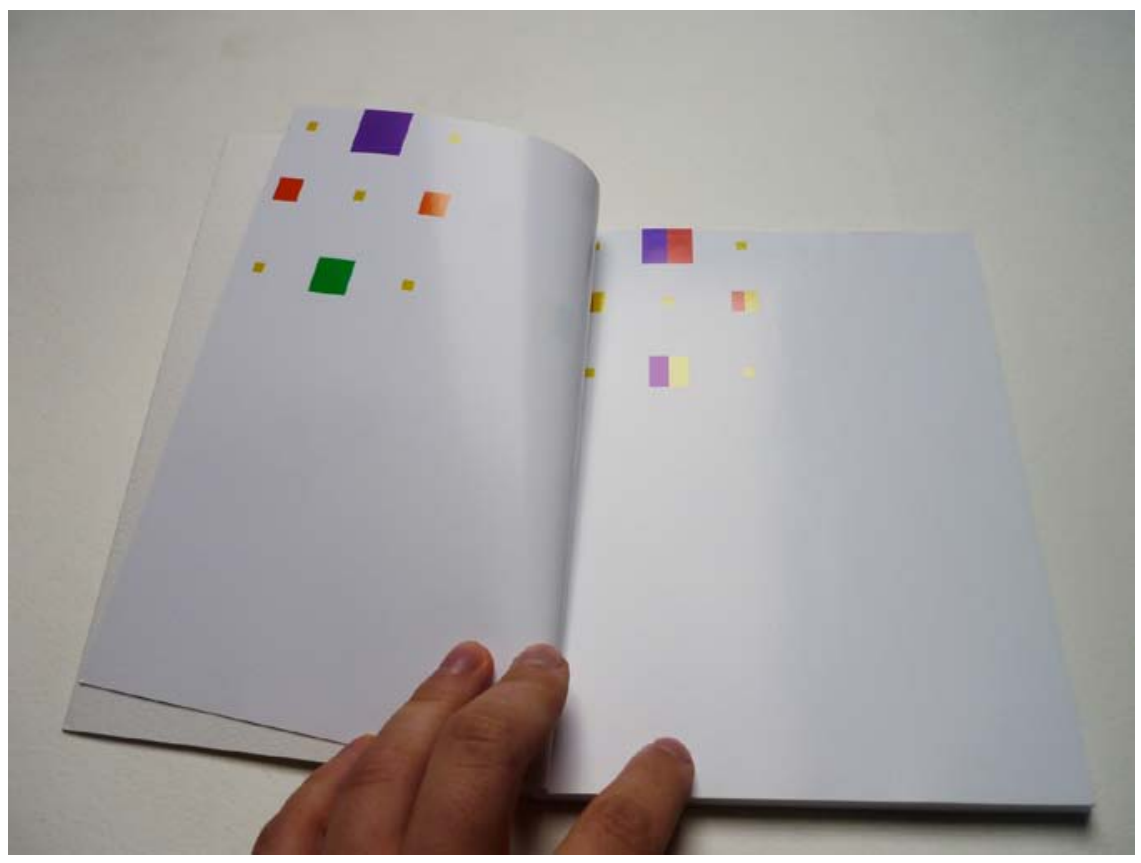

FIGURE 12.7 Lambeens, Front Back (Hasselt: UHasselt/Het Onrijpheid, 20o9), p. 2.

narrative sequence, divided into three chapters respectively entitled "yellow," "red" and "blue," consists of the changing of these squares' colour, size and position on the spread. The immediate assumption is that the sequence of these squares is no coincidence, so one begins to "read" the squares and their changing position, colour and shape, as a code. At first glance, Front Back takes the coding of colour and form that can also be found in Jimmy Corrigan, to the extreme. And indeed, different "clues" to its decoding can be found: the size of the squares is influenced by the used colour (small for yellow, larger for blue), the set of squares rotate along a pattern of a cross and a lozenge, a secondary colour is divided into its primary colours in an ensuing page and the spread of the squares follows certain proportions with utmost precision (Figure 12.7). One can even construct a narrative: the sequence of squares can be "decoded" as a radical abstraction of a life story. In the first "yellow" chapter, all squares are situated at the top of the page, and on each page five small, vibrantly yellow squares return. The brightness of yellow and the relative simple rotations of the squares could be said to resemble the optimistic beginnings of life. The final chapter, by contrast, is dominated by the colour blue. The squares have now become bigger and have "sunk" to the bottom of the page, suggesting passivity and death (Figure 12.8). It also seems to be no coincidence, then, that the 


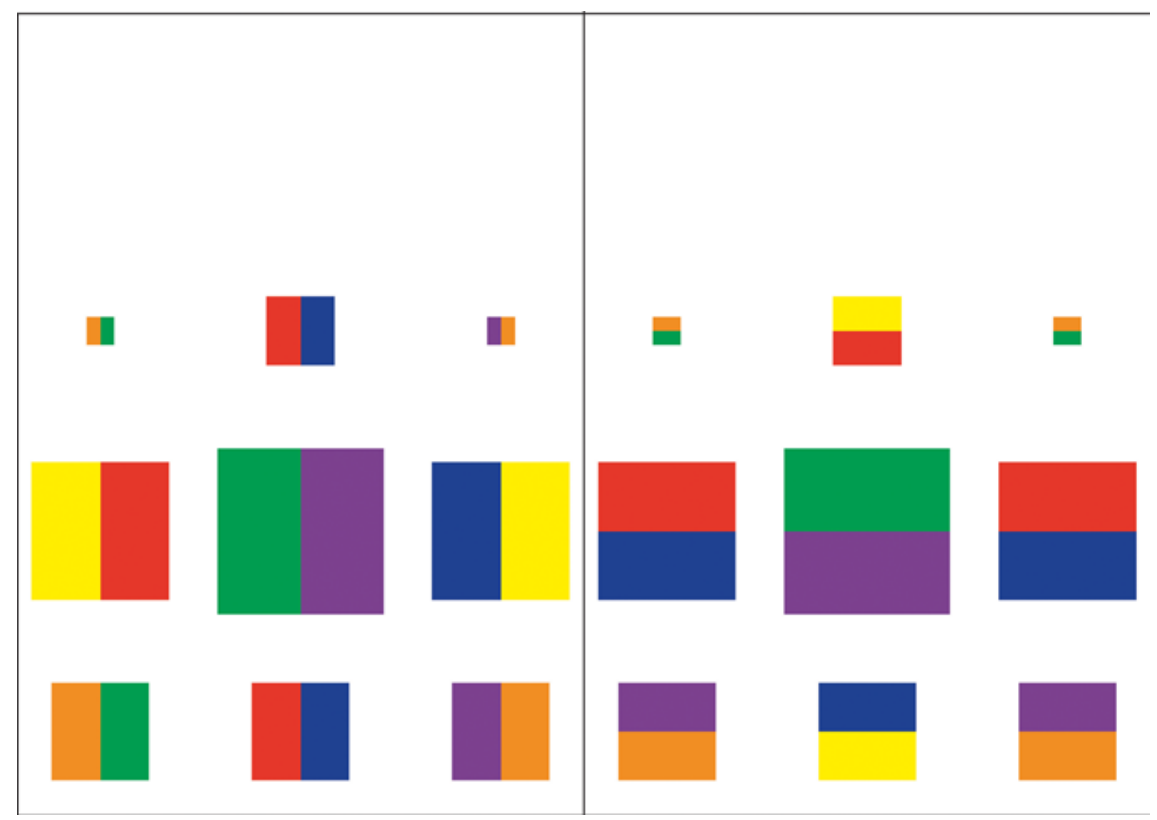

FIGURE 12.8 Lambeens, Front Back (Hasselt: UHasselt/Het Onrijpheid, 2009), p.54.

back of the book is entirely black, while the cover is white: whatever the story might be, the ending is surely not a happy one. All these aspects seem to invite the reader to try and "crack the code" - but at the same time, sensations begin to interact with the codes and interfere with the neat sequence of squares and colours. These sensations are created by taking advantage of the specificity of the medium of comics. Front Back tries to make clear that this specificity does not primarily lie in the combination of written text and images, as Harvey argues, but in these medium-specific possibilities to create sensations that interact with the codes.

Some of these sensations are created by the decision to use a different kind of paper for each chapter: coated ("compressed" fibers) and bright white, glossy paper for the first chapter, uncoated ("open" fibers) and rough, mild yellowish paper for the last one, while the neutral paper of the second chapter functions as a transition between these two extremes. Unlike movies or paintings, a book form allows us to hold the work in our hands, allowing a tactile perception. Literature, of course, uses the same form of the book, but only works with words. In the genre of comic books, however, the quality of the paper can influence the visual perception of the images and hence the "content" of the visual narrative. By using the grain and the thickness of the paper as operative ele- 


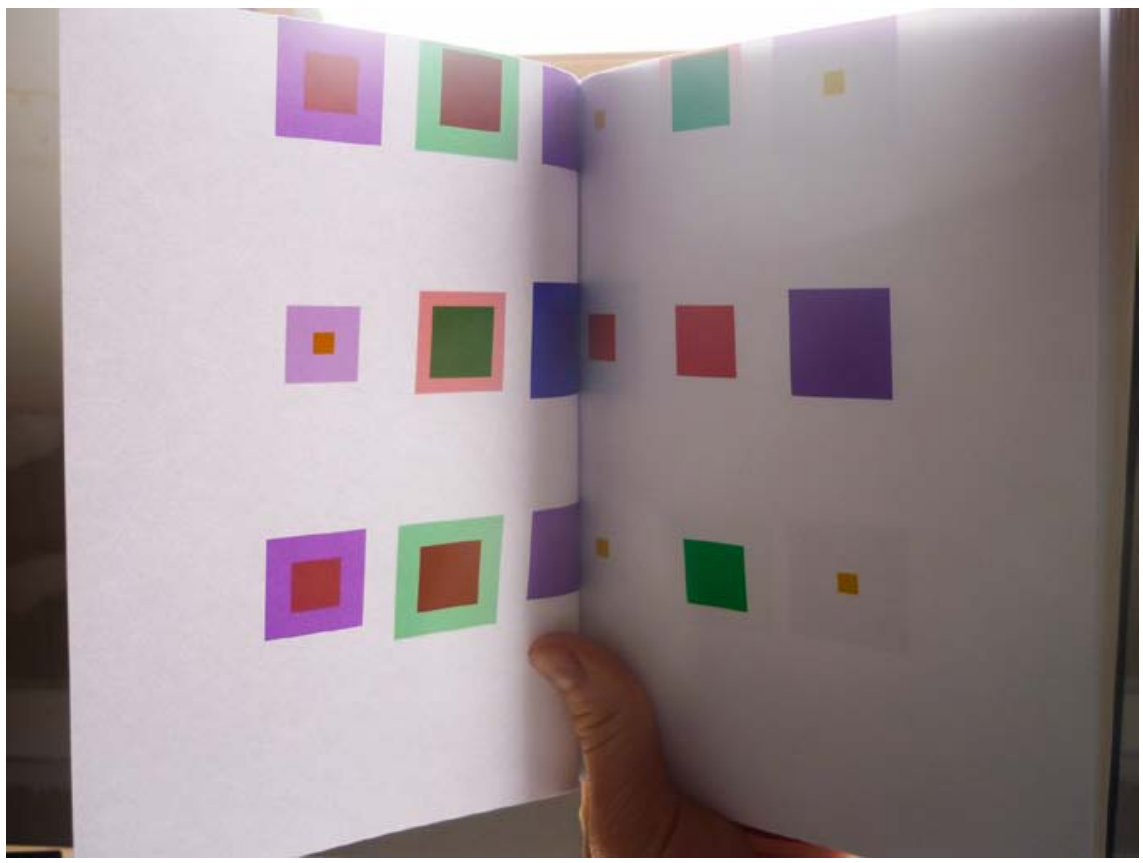

FIGURE 12.9 Lambeens, Front Back (Hasselt:UHasselt/Het Onrijpheid, 20o9), p. 83.

ments of the work itself, interesting side effects are created. Especially in the second, "red" chapter, where the colours on the verso-side already shine through on the recto-side. Because the sheets were deliberately bound before the ink had dried completely, the ink has also stained the opposite page. This creates a "halo" around some of the squares that becomes part of the overallcomposition of the spread (Figure 12.9). Another sensation is the result of the fact that in a comic book more than one image is present on one and the same page. The combination of different sizes and colours creates a strong visual rhythm that transcends the strict codification and appears to resemble Franquin's whimsical style.

Of course, all of these sensations can be reduced to a "code," whereby (e.g.) the smooth, shiny paper represents the vitality of youth, the more rough, thick paper the ruggedness of old age, and the ink stains the imperfections of life. But just like in the work of Blutch, it is this very multitude of codes that can be found in the work, that eventually prevents any clear-cut solution to the "puzzle." 


\section{Conclusion}

Our analysis of the work of Blutch, Van der Meij, Goblet and Lambeens makes clear that the inherent duality between word and image in comic books should not be seen as an insoluble conflict between reading and perceiving. Many experiments in current avant-garde comics focus on the point where both zones become indiscernible, and the sensation starts to disrupt the code and affect the reader/viewer. Their works demonstrate how an intelligent combination of code and sensation in fact reveals the distinctive possibilities of the comic genre in comparison to other, more established genres like film, literature or painting. We hope to have demonstrated that in order to fully grasp these possibilities, comic strip theory needs to extend its predominantly semiotic vocabulary by taking into account the pictorial qualities of comic book images. Therefore, a notion like "sensation" should not be restricted to a strictly philosophical, Deleuzian approach of high modernist art, but can also be turned into an interesting conceptual tool to analyse and create modern comics.

\section{Secondary Literature}

Christiansen, H.-C., "Comics and Film: A Narrative Perspective," in Comics \& Culture: Analytical and Theoretical Approaches to Comics, eds. A. Magnussen and H.-C. Christiansen (Copenhagen, 2000), pp. 107-23.

Deleuze, G., Francis Bacon: The Logic of Sensation [translated by D.W. Smith] (New York, $2003[1981])$.

Dierick, Ch. and P. Lefèvre, 1998. "Introduction," in Forging a New Medium. The Comic Strip in the Nineteenth Century, eds. Ch. Dierick and P. Lefèvre (Brussels, 1998), pp. 9-36.

Groensteen, Th., "Un premier bouquet de contraintes," in OuPus 1 / OuBaPo (Ouvroir de Bande Dessinée Potentielle) (Paris, 1997), pp. 13-59.

—, The System of Comics, trans. B. Beaty and N. Nguyen (Jackson, Miss., 2007 [1999]).

—_L La Bande Dessinée: Mode d'Emploi (Brussels, 2008).

Harvey, R.C., "Comedy at the Juncture of Word and Image: the Emergence of the Modern Magazine Gag Cartoon Reveals the Vital Blend," in The Language of Comics: Word and Image, eds. R. Varnum and Ch. T. Gibbons (Jackson, Miss., 2007), pp. 75-96.

Lefèvre, P. and J. Baetens, Strips anders lezen (Amsterdam/Brussels, 1993).

—_, "Recovering Sensuality in Comic Theory," in International Journal of Comic Art 1(1) (1999), pp. 140-49. 
"The Battle over the Balloon: The Conflictual Institutionalization of the Speech Balloon in Various European Cultures," in Image and Narrative 14 (2006). Accessible at: http://www.imageandnarrative.be/inarchive/painting/pascal_levevre.htm McCloud, S., Understanding Comics. The Invisible Art (Northampton, Mass., 1993). Peeters, B., Case, planche, récit. Comment lire une bande dessinée (Tournai, 1991). Peeters, B. and J. Samson, Chris Ware: La bande dessinée réinventée (Brussels, 2010). Shklovsky, V., "Art as Technique," in Russian Formalist Criticism: Four Essays, eds. L.T. Lemon and M.J. Reis (Lincoln, 1965), pp. 5-24.

\section{Comics Cited}

Arntz, G., Pictogram of a boat (1930). Accessible at http://www.gerdarntz.org/isotype Blutch, Le cavalier blanc numéro 2 (Chatenay Malabry: Alain Beaulet, 2002). _- Le Petit Christian, tome 1 (Paris: L'Association, 1999).

Franquin, Zwartkijken (Doornik: Glad ijs/Casterman, 2008).

_- Die Reuze Flater (Brussel: Dupuis, 2009).

Gerner, J., TNT en Amérique (Paris: Lampoule, 2002).

Goblet, D., Faire Semblant C'est Mentir (Paris: L'Association, 2007).

Hergé, De Zonnetempel (Doornik: Casterman, 1977).

Lambeens, T., Front Back (Hasselt: UHasselt/Het Onrijpheid, 2009).

Van der Meij, B., De Winnaar (Amsterdam: Sherpa, 2005).

Ware, Ch., Jimmy Corrigan: The Smartest Kid on Earth (New York: Pantheon, 200o). 
PART 4

Reception and Literary Infrastructure 